\title{
The Megalithic civilisation in Switzerland, its society and its monuments
}

\author{
Pauline Maillard ${ }^{1}$ and Jérôme Berti ${ }^{2}$ \\ ${ }^{1}$ Section archéologie, Faculté de Lettres, \\ Université de Lausanne, Switzerland \\ email: pauline.maillard@unil.ch \\ ${ }^{2}$ Faculté des Hautes Etudes Commerciales, \\ Université de Lausanne, Switzerland \\ email: jerome.berti@unil.ch
}

\begin{abstract}
The Swiss megaliths, just like the English sites, hold an obvious interest for archaeology and astronomy. Within the sites located in Switzerland, the megaliths of Corcelles-Concise have some particular characteristics which are, in our opinion, relevant to point out. Indeed, using recent astronomical software, we have been able to attribute to this site a probable astronomical function. This lead us to wonder about the general use of this kind of location, with some insights on a cultual plan.
\end{abstract}

Keywords. Megaliths, neolithic, Switzerland

\section{Introduction}

Our field of observation focused on Switzerland during the 5th and 4th millennia BCE. At that time, agricultural and pastoral societies are thought to have complex social functioning. It is in this new Europe that multiple and involved rites are going to appear. They may have foreshadowed the construction of megalithic structures varying in shapes and significations. The site of Corcelles-Concise $\left(46^{\circ} 55^{\prime} 55^{\prime \prime} \mathrm{N}, 6^{\circ} 42^{\prime} 30^{\prime \prime} \mathrm{E}\right)$ in question is an rudimentary megalithic group, formed by four stones among which one has been replaced in the modern period, the stones heights are between 150 and $240 \mathrm{~cm}$. On the eastern menhir, a dozen engravings form small cavities.

In 1994, excavations revealed the existence of two other existing menhirs buried in a pit filled with pebbles, in the extension of the South and East menhirs. The lack of absolute datation, of vestiges or of archaeological remains in direct association with the megalithic structure does not enable us to precisely date their stages of construction. On the other hand, some indirect indications would situate the emergence of megalithism in Switzerland around the beginning of Middle Neolithic. This is possible to determine by stylistic comparisons with some French lithic buildings. In Corcelles-Consise, the analysis of scarce and fragmented potery confirms these datation hypothesis.

\section{Overview}

Once the establishment of a plan is done, they appear to be forming a trapezium as it can be observed in Fig. 2.

By determining the azimuths in the different axes, it becomes possible to notice their correlation with the astral rises and sets. To emphasise these probable alignments, it is nowadays easy to simulate the sky at the time (Middle Neolithic) and to note the rise and set of major stars, as well as the Sun and the Moon. These simulations can be carried 


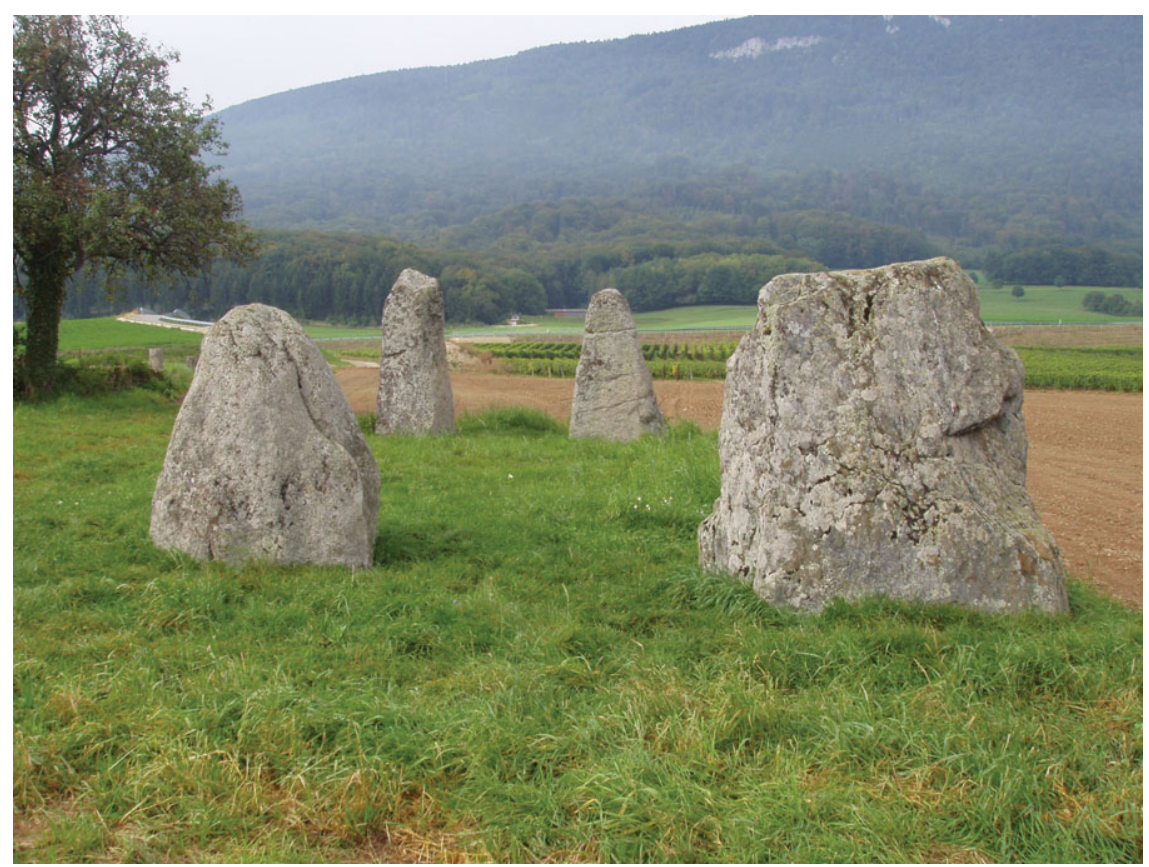

Figure 1. The archaeological site of Corcelles-Concise $(\mathrm{CH})$.

Table 1. Computerised results

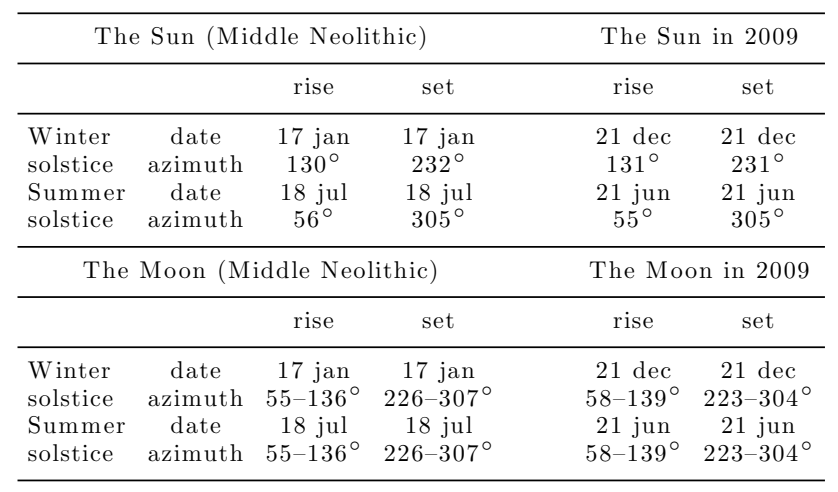

out with software such as Starry Night Pro. The latter reliably and precisely enables the compensation of the phenomenon of precession and nutation. It is also possible to insert the exact field of view of the landscape. Information techniques greatly improve the quality of the field results.

As expected, the precession-nutation phenomenon influences the solstices' dates but not really the positions of risings and setings. Then the azimuths determined by the axes can be compared to computerised measures. They enable the observations of the following examples:

(a) The axis $F$, indicating $133^{\circ}$, corresponds to the sunrise at winter solstice to within $3^{\circ}$. On the same day, the sunset seems to be indicated by axis $C\left(235^{\circ}\right)$. That is to say a gap of again $3^{\circ}$.

(b) The axis $C$ points towards the sunrise at summer solstice, to within $1^{\circ}$. The sunset does not seem to be inscribed. 


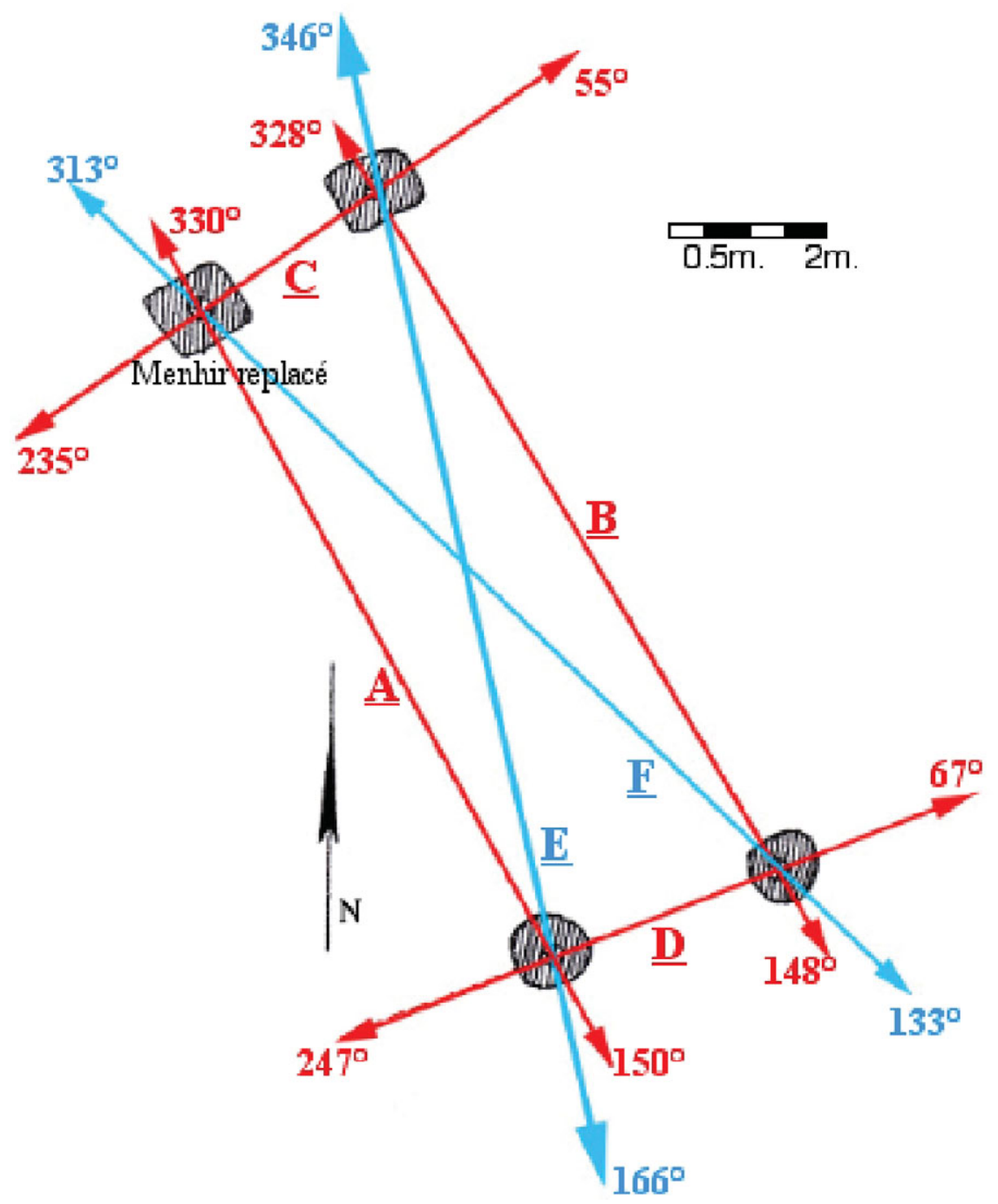

Figure 2. Diagramme of Corcelles-Concise $(\mathrm{CH})$.

(c) Within an acceptable margin of error, the amplitude of the moonrise is between the axes $C\left(55^{\circ}\right)$ and $F\left(133^{\circ}\right)$. Once again the extrema of the moonsets are not inscribed. The site of Corcelles-Concise seems to be mainly aligned on the sunrises and the moonrises, whereas the sets of these heavenly bodies are not presented. It is crucial to keep in mind that the newly replaced stone could distort the interpretation of the site.

With this study, we have been able to verify that the megalithic sites are built in such a way that they are modelled on the solar, lunar and stellar movements and that they are much more widespread than the current studies lead us to believe. Indeed the structures, qualified as "astronomical observatories", indicate the major astronomical events. In our opinion they are not limited to the biggest complexes such as Stonehenge. It is indeed what is demonstrated by our study on the sites of French-speaking side of Switzerland. Even though this lithic building is relatively simple, the megalithic structure points towards axes corresponding to the movements of the Sun and the Moon at winter 
and summer solstices. The rises of the two bodies seem, here, to be better inscribed than their sets.

\section{Function of the site}

The inscription of the solar and lunar movements on the stone buildings might have had a predominant structure for the central European societies living off agriculture and farming in the Neolithic. Indeed the knowledge of astronomy should not be surprising as it was a necessity. It would be absurd to imagine this comprehension as of secondary importance in societies depending on the development of the seasons. Being able to determine them by using the dates of the solstices certainly improved the quality of life of these societies based on agriculture. Precisely knowing the rhythm of the seasons allowed farmers to protect their harvests by anticipating any kinds of phenomena such as risks of frost.

\section{Conclusion}

Even if the empirical proofs are almost inexistent, the cultual connotation of these sites should not be minimised. It is very likely that the locations with possible astronomical observations characteristics also had religious functions. Moreover it is pertinent to imagine the matching up with a cult linked to fertility celebrating the renewal of nature, as the extensions of days announcing the Summer and the upcoming harvests.

\section{References}

Allenbach, W. 2002, Guide des sites religieux du Nord-Vaudois (Yverdon-les-Bains: Imprimerie du Journal d'Yverdon)

Aubert, E. 2005, Histoire d'Yverdon; Tome 1: Des temps préhistoriques à la conquête bernoise (Yverdon-les-Bains: Ed. Schaer)

Gaillard, F. 1897, Les Sciences Populaires, revue mensuelle internationale d'astronomie de météorologie et des sciences d'observation, $1, \mathrm{x}$

Gallay A. 2006, Les sociétés mégalithiques. Pouvoir des hommes, mémoires des morts (Lausanne: Presses polytechniques et universitaires romandes)

Mohen, J.P. 2003, Cultes et rituels mégalithiques (Tours: La maison des roches)

Moinat, P. \& Gallay, A. 1998, Archéol. suisse, 21, 2

Wüthrich, S. 2003, Saint-Aubin/ Derrière la Croix : Un complexe mégalithique durant le Néolithique moyen et final (Neuchâtel: Ed. du Ruau) 